\title{
EDITORIAL
}

\section{Cataract surgery teaching}

\section{Ensino da cirurgia de catarata}

Eduardo Sone Soriano

Similar to any educational process, surgical teaching should follow a methodology that can be reproduced and compared. In accordance with scientific methodology, goals should be established and results measured with the use of progress indicators and complication rates as evaluation elements.

Teaching strategies may differ; however, methodologies must be standardized rather than different instructors teaching in different ways based on what they feel is best ${ }^{(1,2)}$. In 2004, the Federal University of São Paulo established a teaching methodology we termed, "backward," as teaching institutions in Japan were using a similar instructional model. The term "backward" refers to the idea that complications at the end of surgery are less morbid than those occurring at the beginning of surgery. In 2007, this methodology was successfully introduced at the teaching hospital, Santa Casa de São Paulo, leading to a decrease in the number of documented complications.

The "backward" methodology involves dividing surgery into five stages: the instructor performs the first four stages and the student performs the last stage. As the student gains mastery of the last stage, successfully completing at least five procedures, the student is then allowed to move backward and gradually assume responsibility for the performance of earlier stages in a retrograde manner. It is important that all procedures are documented in a control logbook. In 2008, a group of doctors with an interest in cataract surgery teaching improved the method and attempted to extend it to residency programs affiliated with the Brazilian Council of Ophthalmology in collaboration with a pharmaceutical company ${ }^{(3)}$. Although all stakeholders had an interest in the project, demands on time, people, and costs requirements prevented the maintenance of this project.

First-year residents are exposed to theoretical and some practical experience in cataract surgery. The largest acquisition of competence occurs in the second year, and residents continue to refine their skills and gain confidence in the third year. Students wishing to advance in the field of ophthalmology can specialize in cataract surgery, gain experience of more complex cases, and pursue fellowship programs.

The balance between quantity and quality presents a substantial dilemma. The best synopsis is the completion of a large quantity of quality procedures; however, if I had to pick one, it would be the latter. As in sports activity, improvement comes with repetition, and proper guidance shortens the learning curve, avoids the development of poor habits, minimizes complications, and saves resources. However, providing an environment that ensures both quantity and quality is challenging, particularly when considering that the main teaching theaters in Brazil are in academic centers, supported by a public service structure. Resources are often lacking, leading to an inadequate supply of good quality equipment and materials. Further, funding aimed at ensuring the presence of qualified instructors in a 1:1 teaching ratio remains insufficient.

Some teaching programs set a minimum number of surgeries to ensure mastery. For example in the United States, the Accreditation Council for Graduate Medical Education requires residents perform a minimum of 86 cataract surgeries during the three years of residency. In Brazil, the Brazilian Council of Ophthalmology recommends that programs offer at least 150 surgical procedures in general; however, there is no specific stipulation regarding the quantity or type of procedure offered. However, the International Council of Ophthalmology does outline the specific skills that should be mastered during residency, allowing the performance of routine and advanced cataract surgery and intraocular lens placement. Studies have indicated the complications rate of resident-performed cataract surgery falls by $50 \%$ after the first 40 cases and becomes acceptable after approximately 100 cases $^{(4,5)}$.

The application of a standardized teaching methodology also provides students of lower natural ability with adequate scaffolding and support and minimizes complications that can lead to devastating physical consequences for patients and emotional consequences for both patients and surgeons. Further, medico-legal issues, which are continuously growing and can last over periods of years, may severely impact the careers of doctors.

Submitted for publication: June 8, 2015

Accepted for publication: June 9, 2015

Associate Editor, ABO.
Funding: No specific financial support was available for this study.

Disclosure of potential conflicts of interest: The authors have no potential conflicts of interest to disclose.

Corresponding author: Eduardo S. Soriano. Rua Botucatu, 821 - São Paulo - SP - 04023-062 Brazil - E-mail: dusoriano@gmail.com 
The teaching of small incision extra capsular extraction, which does not preclude phacoemulsification, represents another complex issue that I believe is important in some locations due to lower associated costs. Also, this procedure still has utility in certain situations including the absence of phacoemulsification equipment, conversion in cases with complications, and, in particular circumstances, such as a very hard nucleus associated with severe zonular damage.

In my view, the teaching of cataract surgery is based on five pillars: (1) the study of theory through books, with particularly in-depth understanding of "phacodynamics" when learning of phacoemulsification; (2) access to wet labs and virtual simulators, which always must precede practice on human eyes; however, costs currently make this practically unavailable; (3) assistance and observation in live surgery and the use of surgical videos; (4) assisted practice with an experienced instructor ready to identify and prevent high-risk situations, and record surgeries for further review; and (5) continuing education to update the surgeon on new advances and technical changes, such as the possible application of femtosecond lasers.

Challenges in cataract surgery education include increasing accessibility to good-quality teaching centers in all areas of the country for both ophthalmologists in training or those who have already graduated. There are many ophthalmologists who have not had the opportunity to learn or wish to renew their skills. Increasing accessibility requires investment in educational programs, not only infrastructure, but mainly in personnel to ensure experienced surgeons are available for teaching. Unfortunately, with the current economic conditions in Brazil and the apparent lack of interest in education, this reality is becoming more and more distant.

\section{REFERENCES}

1. Kloek CE, Borboli-Gerogiannis S, Chang K, Kuperwaser M, Newman LR, Lane AM, et al. A broadly applicable surgical teaching method: evaluation of a stepwise introduction to cataract surgery. J Surg Educ. 2014;71(2):169-75.

2. Ghanem VC, Mannis MJ. O professor e o estudante na facoemulsificação: os dez princípios para o sucesso. Arq Bras Oftalmol. 2003;66(1):93-9.
3. Fischer AF, Pires EM, Klein F, Bisneto OS, Soriano ES, Moreira H. Programa de ensino de facoemulsificação CBO/ALCON: resultados do Hospital de Olhos do Paraná. Arq Bras Oftalmol. 2010;73(5):517-20.

4. Ament CS, Henderson BA. Optimizing resident education in cataract surgery. Curr Opin Ophthalmol. 2014;22(1):64-7.

5. Corey RP, Olson RJ. Surgical outcomes of cataract extractions performed by residents using phacoemulsification. J Cataract Refract Surg. 1998;24(1):66-72.

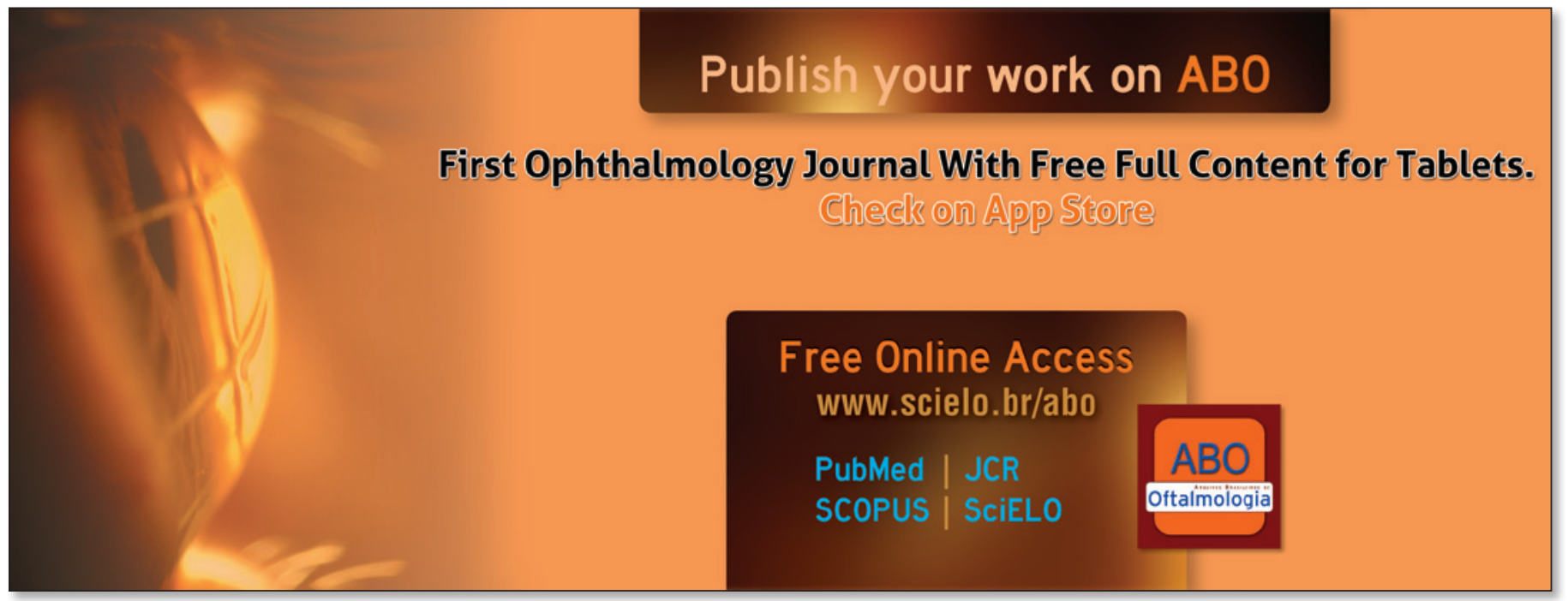

